\title{
Eagle Syndrome Presenting with Neurological Symptoms
}

\author{
Elcin AYDIN¹, Huseyin QULIYEV², Celal CINAR², Halil BOZKAYA², Ismail ORAN² \\ ${ }^{1}$ Baskent University, School of Medicine, Department of Radiology, Izmir, Turkey \\ ${ }^{2}$ Ege University, School of Medicine, Department of Radiology, Izmir, Turkey \\ This study has been presented as a poster presentation at the $36^{\text {th }}$ National Radiology Congress in 2015
}

\section{ABSTRACT}

\begin{abstract}
AIM: Eagle syndrome is a rare entity that causes recurrent throat pain, neck pain, dysphagia, or facial pain due to an elongated styloid process or calcified stylohyoid ligament. Clinical findings related to lower cranial nerve compression have also been reported. In some cases, it is reported that carotid artery compression or dissection can be seen due to elongated styloid process and this is called carotid artery syndrome. Carotid artery compression causes flow reduction and carotidynia or neurological symptoms can be seen. Dural sinuses and the jugular vein can be compressed. Eagle syndrome with neurological symptoms has been rarely reported.

MATERIAL and METHODS: The data of 5 patients (aged between 22 and 68 years), who presented to the hospital with various neurological symptoms, were retrospectively reviewed. Each patient underwent computed tomography (CT) that revealed a long styloid process.

RESULTS: An elongated styloid process caused neurological symptoms. Two patients had venous compression by the styloid process and the other patients had transient ischemic attacks due to internal carotid artery compression by the styloid process. Only one patient underwent surgical removal. All patients' outcomes were good after treatment and no symptoms remained.

CONCLUSION: Eagle syndrome may be presented with neurological symptoms. It should be kept in mind in the differential diagnosis of patients who have neurological symptoms without any objective etiological factors. To the best of our knowledge, Eagle syndrome with arterial and venous compression due to elongated styloid process has not been previously presented in the literature.
\end{abstract}

KEYWORDS: Eagle syndrome, Styloid process, Neurological symptom

\section{INTRODUCTION}

$\mathrm{E}$ agle syndrome results from elongation of the styloid process or mineralization of the stylohyoid or stylomandibular ligaments. The styloid process arises from the base of the temporal bone and lies caudally, medially and anteriorly nearby the carotid arteries, internal jugular vein and cranial nerves VII, IX, X, and XII $(11,12,14,17)$. A styloid process greater than $3 \mathrm{~cm}$ is defined as elongated (1). The styloid apparatus is derived by migration of Reichart's cartilage from the second brachial arch to the temporal region (11-14). The incidence of an elongated styloid process is reported to be between $4 \%$ and $28 \%$ and is mostly seen in women (15).
Eagle syndrome includes symptoms such as pharyngeal pain, sensation of foreign body lodged in the pharynx, dysphagia and odynophagia $(7,10,19)$. Some publications have reported transient neurological symptoms, such as hemiparesis and speech disturbance, caused by internal carotid artery compression by the styloid process $(7,13,18)$. The tip of an elongated styloid process projects between the internal and external carotid arteries which causes headache or pain in the infraorbital, temporal, and mastoid regions (20).

A lateral neck radiograph, orthopantomogram, and modified Towne's view can confirm the diagnosis, but three-dimensional (3D) computed tomography (CT) scan is the most valuable 
diagnostic tool that can define the anatomic relationship between the elongated styloid process and the vascular structures and nerves (2).

In our report, five patients with neurological symptoms due to Eagle syndrome are presented and the clinical significance is discussed based on contemporary literature data.

\section{- MATERIAL and METHODS}

From June 2009 to May 2016, 5 patients with Eagle Syndrome presented to the hospital with different neurological symptoms. The data of these patients were reviewed retrospectively. All patients underwent CT (Somatom Sensation 64, Siemens, Erlangen, Germany) and 1.5 Tesla magnetic resonance imaging (MRI) (Magnetom Vision, Siemens, Erlangen, German) examinations. 3D volume-rendering CT images were created and one patient (Case 3) was diagnosed with conventional angiography. All patients' outcomes were classified using the Karnofsky Performance Scale Index which allows patients to be classified according to their functional impairment. This can be used to compare the effectiveness of different therapies and to assess the prognosis in individual patients.

\section{Case 1}

A 32-year old man presented with a 4-month history of headache and walking disturbance. He complained about pulsatile headache and photophobia. The patient underwent a thorough evaluation by a neurologist for his headache and was diagnosed with migraine. After migraine therapy, his symptoms still remained and MRI was performed. MRI and MRI-venography suggested possible right transverse-sigmoid sinus thrombosis. A subsequent CT-angiogram was performed the next day and it confirmed the pathology. Coronal and 3D volume-rendering CT images showed bilateral long styloid process and right transverse-sigmoid sinus thrombosis related to the right jugular vein compression by the styloid process (Figure 1A-D). Long-term anti-coagulation was recommended for treatment. He reported complete resolution of all symptoms and his neurological examination was normal.

\section{Case 2}

A 22-year old man suffered from headache for two months. He was treated unsuccessfully with anti-migraine drugs. Papilledema was found on neurological examination and then MRI was performed. MRI showed hypoplastic right transverse sinus. For further examination, the patient was investigated with CT scan that clearly showed a hypoplasic right transverse sinus and compressed left internal jugular vein between the $\mathrm{C} 2$ transverse process and calcified styloid ligament (Figure 2A-D). Complete resolution of the papilledema was seen after anti-edema medications. Visual field and fundus examinations were normal. At 2-year follow-up, the patient was asymptomatic.

\section{Case 3}

A 39-year-old man presented with recurrent speech

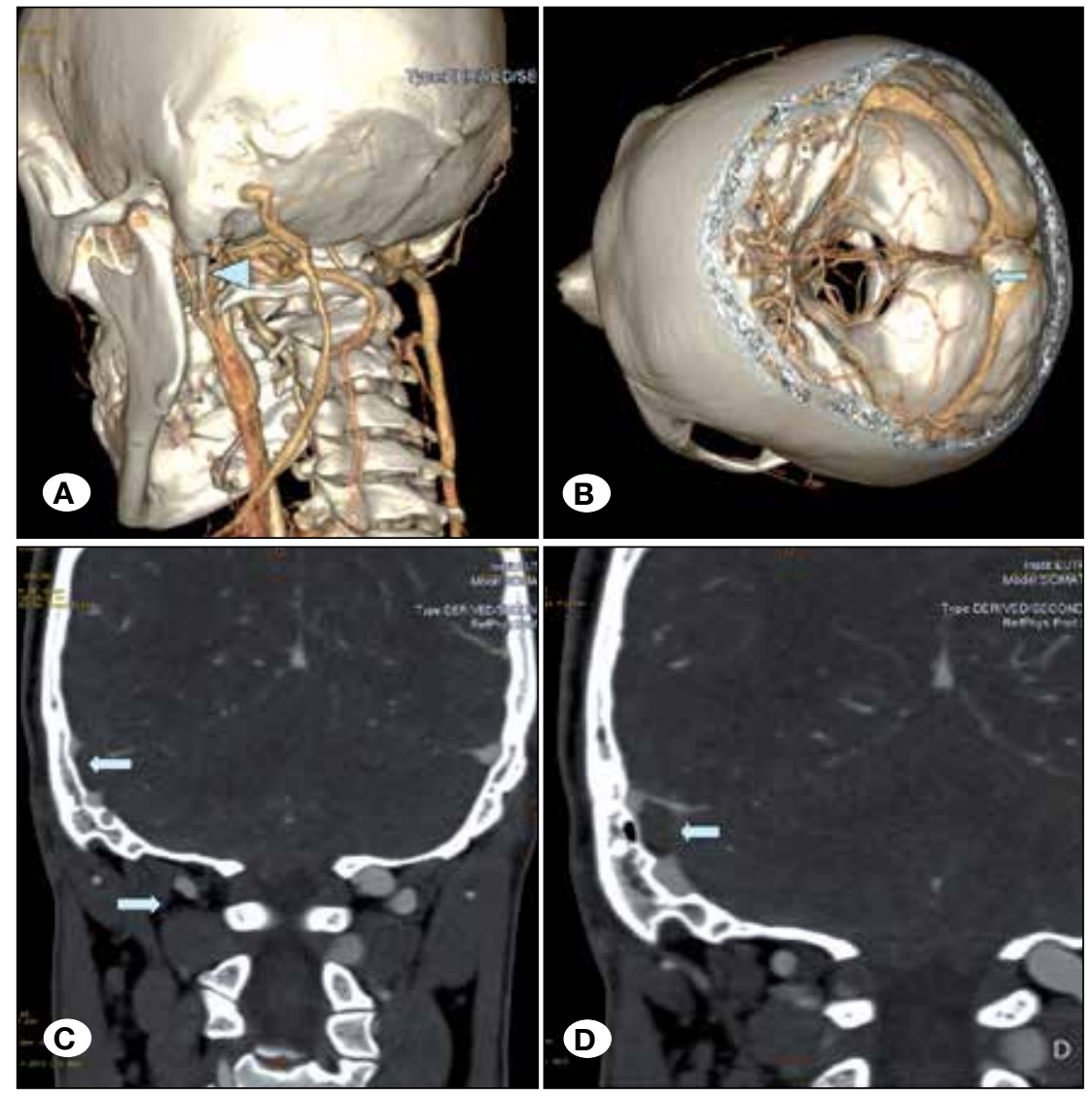

Figure 1: 3D volume-rendering CT images show bilateral long styloid process and right transverse-sigmoid sinus thrombosis related to the right jugular vein compression by the styloid process (A,B). Coronal CT (C, D) images demonstrate transverse sinus thrombosis (arrows). 
disturbance and right numbness. No abnormalities except right hemihypoesthesia could be detected during the neurological examination. MRI and diffusion MRI showed left parietal lobe subacute ischemia while CT angiography and conventional angiography revealed bilateral long styloid process and left cervical internal carotid artery (ICA) loop caused by the abnormal left styloid process (Figure 3A-D). As a result of compression of the left ICA, the patient developed ischemia in the parietal lobe region. Based on the clinical and radiological findings, surgical resection via an extraoral approach (submandibular incision) under general anesthesia was considered the treatment of choice. The patient underwent surgical removal of a $1.5-\mathrm{cm}$ abnormal styloid process. At the 20-month follow-up, the patient remained free of hypoesthesia. Control MRI and diffusion MRI showed no new ischemia and CT-angiography revealed that the compression of the left ICA had disappeared.

\section{Case 4}

69-year-old male patient presented with recurrent transient weakness related to the right cerebral hemisphere. After neurological examination, the patient underwent MRI. Chronic microvascular ischemic changes were found especially in the right cerebral hemisphere. CT-angiography with 3D volume rendering revealed an abnormally long right styloid process compressing the right ICA accompanied by the fusiform aneurysmal dilatation of the artery (Figure 4A-D). The patient was not suitable for surgery or endovascular treatment due to the co-morbidities and was managed with life-long antiaggregant therapy. In follow-up period, no more symptoms occurred and neurological examination findings were better than at the beginning.

\section{Case 5}

A 57-year-old female patient suddenly complained of dizziness and sightedness. On neurological examination, left central facial paralysis and left hemiparesia were found. MRI showed encephalomalacia due to a right middle cerebral artery (MCA) infarct. CT-angiography revealed right MCA infarct and right ICA dissection in the postbulbar segment. CT-angiography also demonstrated bilateral elongated styloid processes consistent with Eagle syndrome (Figure 5A-D).
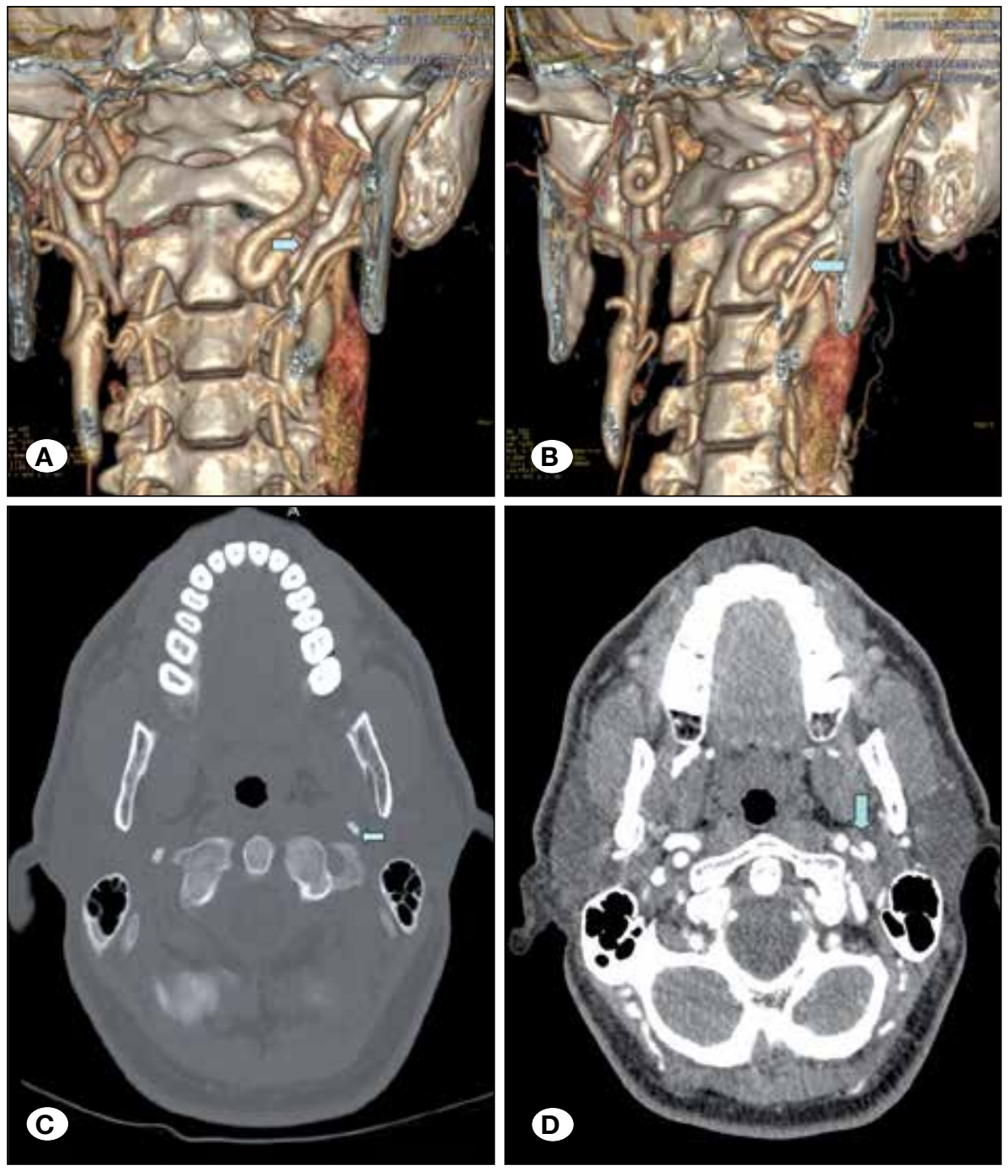

Figure 2: 3D volume-rendering CT images show hypoplasic right transverse sinus and compressed left internal jugular vein between the $\mathrm{C} 2$ transverse process and calcified styloid ligament (A,B). Axial CT $(\mathbf{C}, \mathbf{D})$ images demonstrate calcified styloid ligament (arrow). 

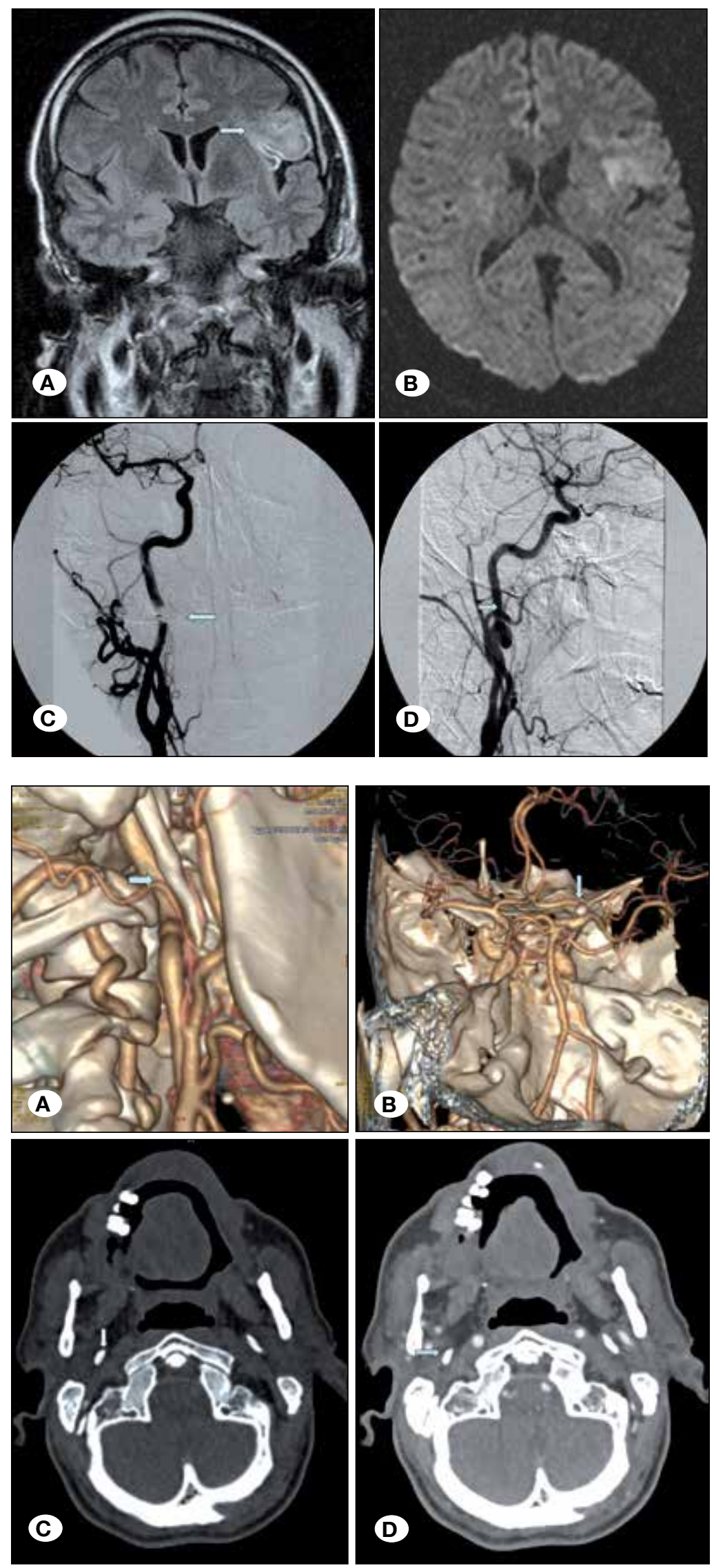

Figure 3: Coronal FLAIR MRI scan (A) and diffusionweighted $\mathrm{MRI}$ scan $(\mathbf{B})$ reveals ischemia in parietal region. Digital subtraction angiography images show bilateral long styloid process and left cervical ICA loop caused by the abnormal left styloid process. Compression of the left ICA developed as a result (C,D).
Figure 4: 3D volume-rendering $C T$ images $(\mathbf{A}, \mathbf{B})$ and axial CT-angiography images (C,D) reveal abnormally long right styloid process compressing the right ICA accompanied by the fusiform aneurysmal dilatation of the artery (arrows). 
Endovascular treatment could not be used due to the vascular loop in the dissecting segment. Anti-aggregant treatment was recommended for treatment and the outcome was good. At the 32-month follow-up, the patient had no more neurological symptoms or radiological findings.

\section{RESULTS}

Patient information, presenting signs and symptoms, CT findings, treatment and outcomes are summarized in Table I. The data of 5 patients with Eagle Syndrome, aged 22-68 years, who presented to the hospital with various neurological symptoms between 2009 and 2016, were reviewed retrospectively. Four of the patients were male. All patients were referred by neurologists after neurological examination. Each patient underwent CT that revealed a long styloid process. Two patients complaining of headache were diagnosed with venous compression by the styloid process and the other patients with transient ischemic attacks due to ICA compression by the styloid process as demostrated with CT-angiography. Only one patient underwent surgical removal. All patients' outcomes were good after treatment and no symptoms remained.

\section{DISCUSSION}

Eagle syndrome is a rare clinical entity and described as an elongated styloid process or mineralization of the stylohyoid or stylomandibular ligaments that causes cervical and facial pain, sensation of foreign body lodged in the pharynx, dysphagia and odynophagia $(7,10,19)$. The normal length of the adult styloid in an adult is thought to be approximately 2.5 $\mathrm{cm}$ while an elongated styloid is considered $>3 \mathrm{~cm}$. Elongation can be unilateral or bilateral $(1,5,6,9,16,18)$.

Two types of Eagle syndrome have been described. The first type includes cervicofacial pain aggravated by swallowing and the sensation of a foreign body in the throat after tonsillectomy (10). The second type is the "stylo-carotid artery syndrome", and is attributed to impingement of the ICA extracranially by the styloid process $(6,10)$. This can cause compression when turning the head, resulting in a transient ischemic accident or stroke (13).

A few reports have documented neurological symptoms due to compression of the cervical carotid arteries leading to the so-called carotid artery syndrome together with carotidynia or neurological symptoms. A long styloid process involves flow reduction in these arteries (13).
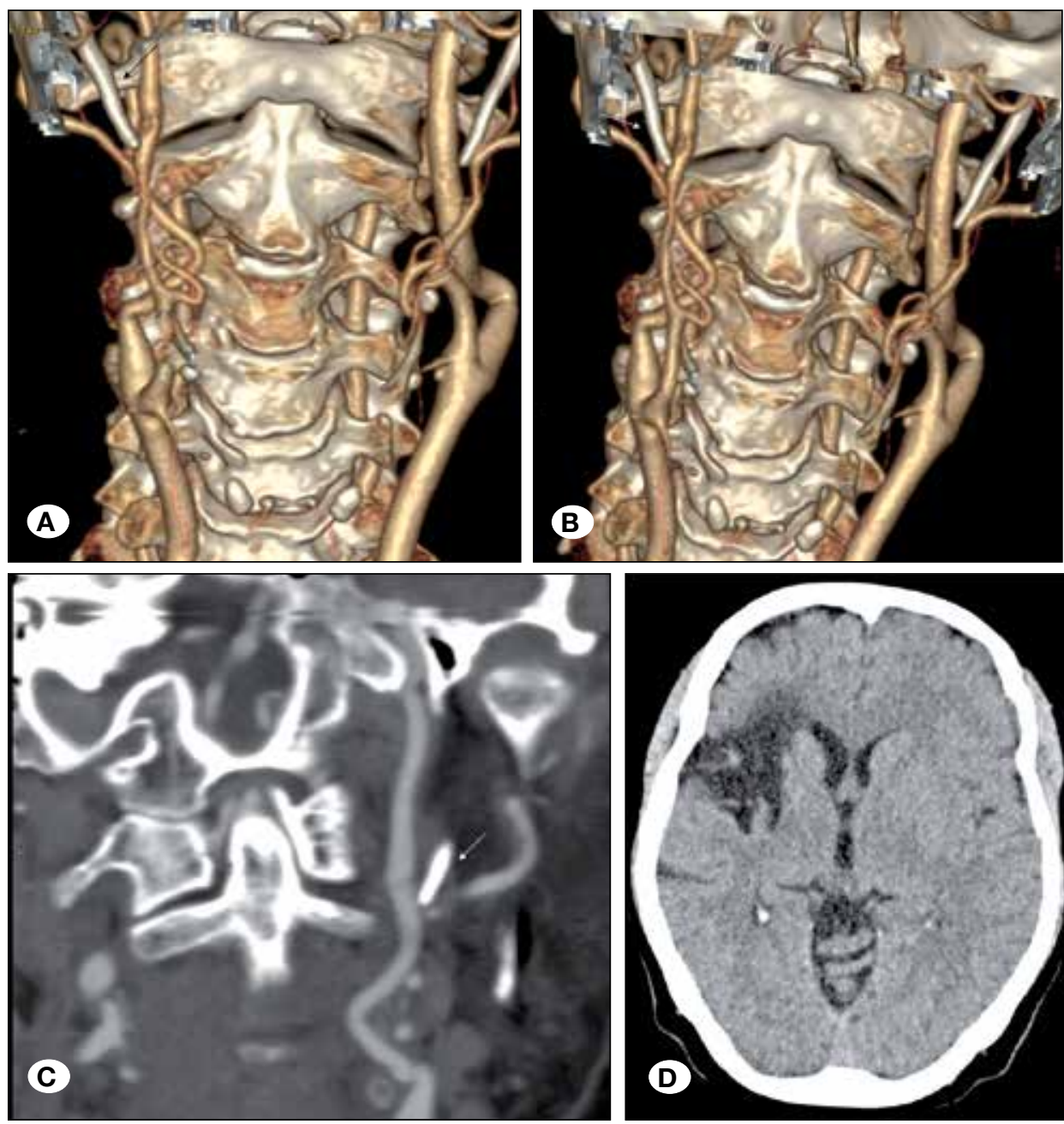

Figure 5: 3D volume-rendering CT images $(\mathbf{A}, \mathbf{B})$ and coronal CTangiography image (C) show bilateral long styloid process (arrows). Axial precontrast CT scan demonstrates chronic right MCA infarct (D). 
Table I: Demographic Information, Presenting Signs and Symptoms, CT Findings, Treatment and Outcomes of the Patients

\begin{tabular}{|c|c|c|c|c|c|}
\hline Case & $\begin{array}{c}\text { Age (yrs)/ } \\
\text { Sex }\end{array}$ & $\begin{array}{l}\text { Symptoms } \\
\text { and Signs }\end{array}$ & CT Findings & Treatment & $\begin{array}{l}\text { Outcome/KPS Index } \\
\text { (before-after } \\
\text { treatment) }\end{array}$ \\
\hline 3 & $39 / M$ & $\begin{array}{l}\text { Recurrent } \\
\text { aphasia and right } \\
\text { hemiparesia }\end{array}$ & $\begin{array}{l}\text { Bilateral long styloid process and left } \\
\text { cervical internal carotid artery loop caused } \\
\text { by the abnormal left styloid process and } \\
\text { as a result of compression of the left ICA } \\
\text { developed ischemia in parietal lobe. }\end{array}$ & $\begin{array}{l}\text { Abnormal } \\
\text { styloid process } \\
\text { was resected } \\
\text { surgically }\end{array}$ & Good /60\%-80\% \\
\hline 4 & $69 / M$ & $\begin{array}{l}\text { Recurrent transient } \\
\text { ischemic attacks }\end{array}$ & $\begin{array}{c}\text { The abnormally long right styloid process } \\
\text { compressing the right ICA accompanied } \\
\text { by the fusiform aneurysmal dilatation of } \\
\text { the artery }\end{array}$ & $\begin{array}{l}\text { Life long } \\
\text { antiaggregant } \\
\text { treatment }\end{array}$ & Good /60\%-80\% \\
\hline 5 & $57 / F$ & $\begin{array}{l}\text { Vertigo and vision } \\
\text { loss }\end{array}$ & $\begin{array}{c}\text { Bilateral long styloid process, right arteria } \\
\text { cerebri media infarct and right internal } \\
\text { carotid artery dissection in the postbulbar } \\
\text { segment }\end{array}$ & $\begin{array}{c}\text { Antiaggregant } \\
\text { treatment }\end{array}$ & Good /50\%-80\% \\
\hline
\end{tabular}

Yrs: Years, M: Male, F: Female, CT: Computed tomography, KPS: Karnofsky Performance Scale, ICA: Internal carotid artery.

Farhat et al. (13) reported a man who suffered from transient ischemic attacks on turning his head to the left and remission of symptoms with the neutral position. Dynamic angiography revealed an elongated styloid process that caused focal flow restriction and was removed surgically. The patient completely recovered from his symptoms after the surgery. Similarly, our patient, who presented with recurrent aphasia and right hemiparesia due to an elongated styloid process, was treated surgically.

Ohara et al. (18) reported a case of ICA dissection and occlusion due to an elongated styloid process. They performed transoral ultrasonography which is useful for showing the absence of a flow signal in the double lumen of the dilated extracranial ICA. They treated the patient with anti-thrombotic drugs. In our patient with transient ischemic attacks, we detected an abnormally long right styloid process compressing the right ICA accompanied by the fusiform aneurysmal dilatation of the artery. We recommended life-long anti-aggregant therapy.

Dao et al. (7) presented a case of Eagle syndrome resulting in an external carotid artery pseudoaneurysm. Aneurysmectomy and local resection of the styloid process were performed for treatment.
Bouzaidi et al. (3) emphasized the importance of radiological examinations and especially 3D volume-rendering CT scan for the diagnosis of Eagle syndrome. In all of our cases, CT and $3 \mathrm{D}$ volume-rendering CT scans were used for the diagnosis.

In Pubmed, there are two cases that describe central venous outflow obstruction secondary to osseous compression of the internal jugular veins at the craniocervical junction $(2,8)$. According to Pubmed, this is the first reported case of Eagle syndrome resulting in sinus thrombosis. Both patients were detected with CT-angiography. The elongated styloid process and sinus pathology were shown with $3 \mathrm{D}$ volume-rendering CT scan. This can be a new form of Eagle syndrome that includes venous thrombosis due to an elongated styloid process. Our patients, who presented with headache, were supposed to be suffering from migraine. Papilledema was found on neurological examination in one of the patients. Headache and papilledema can be seen in central venous thrombosis due to intracranial hypertension. Headache, generally indicative of an increase in intracranial pressure, is the most common symptom in central venous thrombosis. Central venous thrombosis is an important diagnostic consideration in patients with headache and papilledema or diplopia (caused by sixth nerve palsy) even without other neurological focal signs suggestive of idiopathic intracranial hypertension (21). 
Eagle syndrome can be treated conservatively with injection of steroids or long-lasting anesthetics into the lesser cornu of the hyoid or the inferior aspect of the tonsillar fossa in order to relieve symptoms (4). Surgical intervention by excising the elongated styloid may be divided into the intraoral and extraoral approaches. Intraoral approach leaves no external scarring and has low postoperative morbidity and complications (1).

Eagle syndrome is usually described as elongation of styloid process or mineralization of stylohyoid or stylomandibular ligaments that cause pharyngeal pain, sensation of foreign body lodged in the pharynx, dysphagia and odynophagia. However, it is necessary to keep in mind that it can present with neurological symptoms. Headache, ataxia, papilledema, transient ischemic attacks, recurrent aphasia and hemiparesia were some of the symptoms of our cases. The elongated styloid process can compress cranial nerves, internal and external carotid arteries, dural sinuses and the jugular vein. Eagle syndrome can cause serious complications such as carotid artery pseudoaneurysm, carotid artery dissection and dural venous thrombosis.

\section{CONCLUSION}

When dealing with cases of cervical pain or neurological symptoms, Eagle syndrome must be taken into account. Plain radiographs can be helpful, but the most useful examination for diagnosis is $3 \mathrm{D}$ volume-rendering CT scan. Future studies are necessary to find out the relationship between an elongated styloid process and the development of these complications.

\section{ACKNOWLEDGEMENTS}

We thank Mustafa GOK, Serkan GUNEYLI and Mustafa PARILDAR for their contribution in editing the manuscript.

\section{REFERENCES}

1. Al Weteid AS, Miloro M: Transoral endoscopic-assisted styloidectomy: How should Eagle Syndrome be managed surgically? Int J Oral Maxillofac Surg 44: 1181-1187, 2015

2. Andrade MG, Marchionni AM, Rebello IC: Three-dimensional identification of vascular compression in Eagle's syndrome using computed tomography: Case report. J Oral Maxillofac Surg 66: 169-176, 2008

3. Bouzaidi K, Daghfous A, Fourati E, Kechaou I, Jabnoun F, Chtioui I: Eagle's syndrome. Acta Radiol Short Rep 2: 14, 2013

4. Bozkir MG, Boga H, Dere F: The evaluation of elongated styloid process in panoramic radiographs in edentulous patients. Turk J Med Sci 29: 481-485, 1999

5. Ceylan A, Koybasioglu A, Celenk F, Yılmaz O, Uslu S: Surgical treatment of elongated styloid process: Experience of 61 cases. Skull Base 18: 289-295, 2008
6. Chuang WC, Short JH, McKinney AM, Anker L, Knoll B, McKinney ZJ: Reversible left hemispheric ischemia secondary to carotid compression in Eagle syndrome: Surgical and CT angiographic correlation. AJNR Am J Neuroradiol 28: 143145, 2007

7. Dao A, Karnezis S, Lane III JS, Fujitani RM, Saremi F: Eagle syndrome presenting with external carotid artery pseudoaneurysm. Emerg Radiol 18: 263-265, 2011

8. Dashti SR, Nakaji P, Hu YC, Frei DF, Abla AA, Yao T, Fiorella $D:$ Styloidogenic jugular venous compression syndrome: Diagnosis and treatment. Case report. Neurosurgery 70(3): E795-799, 2012

9. David J, Lieb M, Rahimi SA: Stylocarotid artery syndrome. J Vasc Surg 60: 1661-1663, 2014

10. Eagle WW: Symptomatic elongated styloid process: Report of two cases of styloid process-carotid artery syndrome with operation. Arch Otolaryngol 49: 490-503, 1949

11. Eagle WW: Elongated styloid process. Arch Otolaryngol 25 584-587, 1937

12. Eagle WW: Elongated styloid process; Symptoms and treatment. AMA Arch Otolaryngol 67(2): 172-176, 1958

13. Farhat $\mathrm{HI}$, Elhammady MS, Ziayee $\mathrm{H}$, Aziz-Sultan MA, Heros $\mathrm{RC}$ : Eagle syndrome as a cause of transient ischemic attacks. Case report. J Neurosurg 110: 90-93, 2009

14. Feldman VB: Eagle's syndrome: A case of symptomatic calcification of the stylohyoid ligaments. J Can Chiropr Assoc 47(1): 21-27, 2003

15. Keur JJ, Campbell JPS, McCarthy JF, Ralph WJ: The clinical significance of the elongated styloid process. Oral Surg Oral Med Oral Path 61: 399-404, 1986

16. Murtagh RD, Caracciolo JT, Fernandez G: CT findings associated with Eagle Syndrome. AJNR Am J Neuroradiol 22: 1401-1402, 2001

17. Naik SM, Naik SS: Tonsillo-Styloidectomy for Eagle's Syndrome: A review of 15 cases in KVG Medical College Sullia. Oman Med J 26: 122-126, 2011

18. Ohara N, Sakaguchi M, Okazaki S, Nagano K, Kitagawa K: Internal carotid artery dissection caused by an elongated styloid process: Usefulness of transoral ultrasonography. J Stroke Cerebrovasc Dis 21: 918, 2012

19. Piagkou M, Anagnostopoulou S, Kouladouros K, Piagkos G: Eagle's syndrome: A review of the literature. Clin Anat 22: 545-558, 2009

20. Rechtweg JS, Wax MK: Eagle's syndrome: A review. Am J Otolaryngol 19: 316-321, 1998

21. Saposnik G, Barinagarrementeria F, Brown RD Jr, Bushnell CD, Cucchiara B, Cushman M, deVeber G, Ferro JM, Tsai FY: Diagnosis and management of cerebral venous thrombosis. Stroke 42: 1158-1192, 2011 